\title{
THE PLAYBOY MILIEU IN POST-SOCIALIST HUNGARY
}

ZITA $N_{A G Y^{1}}$

\begin{abstract}
By the 1960s, consumer habits focused on the freedom of selfrealisation, independence and the spending of leisure time became solid values in American culture. Values related to sexuality went through dramatic changes and erotics became part of mass culture as magazines designed for men were introduced onto the market. Playboy magazine, the pioneer of a new segment of the printed press, was born in this environment. Read by masses of people, this magazine had a very strong influence on public life in the second half of the twentieth century, and also served as a model for new lifestyle magazines launched onto the gradually expanding publishing market. If we consider the changes taking place in society as being key to its overwhelming success, then the magazine and the set of values represented by it can be subject to scientific investigation. The purpose of this study is to prove the existence of this correlation by comparing the sociological characteristics of two societies situated in different geographic locations at different times.
\end{abstract}

Keywords Playboy, sexuality, magazine, publication, lifestyle, Hungary, postsocialist, mass culture

In Western societies in the second half of the twentieth century, the availability of financial resources increased, so previous shortage societies were replaced by societies of abundance, and as the options available to people as part of their everyday life increased, introversion and experience orientation became increasingly important. Within a shortage society, the everyday lives of people and their potential actions were determined by the limited availability of goods and constraints; they defined reality outside the subjective world, and their relationships were based on a shared reality. In the experience society of abundance, the number of optional actions increased radically, situational

1 Zita Nagy is a PhD candidate at the Institute of Sociology and Social Policy, Corvinus University of Budapest. E-mail address: zita.nagy@oko-kord.hu. 
constraints eased and relationships also became optional. Gerhard Schulze, German sociologist, defines this society as being an experience-oriented one (Schulze, 1992), and explains the transition to the abundance society as being based on the overall impact of four processes. The first process is a robust increase in the supply of goods and services, accompanied by greater demand potential and shorter working time and the simultaneous disappearance of the limitation of access to goods and services. The fourth process relates to perception of society (relationships, family, career, body) as a flexible world that may be shaped in different ways, and the extensive diffusion of this image. For the purpose of our topic, the segmentation of the experience society is affected very strongly by the self-realization milieu, which typically involves highly qualified people living in cities who hold good jobs. This type was typically used as an economic category in the traditional segmentation approach, and it referred to upper-middle class people. Based on age, this characterisation was then applied to people under the age of forty, and more specifically, business people aged twenty to thirty. Playboy magazine, which represented a new revolutionary concept was aimed at this segment of society. The magazine, launched in 1953, was a huge success among rebellious youths as it presented an aspirational lifestyle for the generation. However, it is impossible to take Playboy out of its original environment; it had a different meaning for people living in countries within the socialist political structure. In these countries, which include Hungary, Playboy was the subject of the desire to be elsewhere. It gave a glimpse into a world which was known to exist, but with which very few had had direct experience. Playboy was clearly the pioneer of a new segment of printed press which had a significant influence on the publications of the second half of the twentieth century (through the public debates it generated) and through how it served as an example for new lifestyle magazines launched from time to time on the gradually expanding press market. As a popular and undoubtedly effective product of mass culture, Playboy magazine seems to be an interesting research topic, and a comparison of the reception of this magazine in two societies with fundamentally different characteristics brings up very interesting findings. If the potential readers of American Playboy form a social group that can also be well-defined with scientific instruments, then in another society where the same group does not exist, the failure of the magazine would be predicted. What kind of reception could the magazine, which was a great success in America in the 1960s, expect forty years later in Hungary, an East European post-socialist society that has a fundamentally different structure and set of values? 


\section{PLAYBOY PHILOSOPHY AND CONSUMER SOCIETY}

Playboy is read by men, young businessmen, professors, artists, architects, engineers, and intellectuals who agree on the same common set of values with regard to one thing: for them, the purpose of life is joy; they intend to enjoy every moment of life and to also accept it; they do not wish to suffer. They like their work and are open to the world in every respect, but they have taste and a demand for erotic things; in a word, they want the best. According to Hugh Hefner ${ }^{2}$, Playboy founder, apart from offering light entertainment for men, Playboy magazine has also played a historic role as a pioneer of free speech and the sexual revolution. Consequently, according to Hefner, readers look at Playboy not primarily for its pornographic content (he does not consider the magazine pornographic at all), but to experience the set of values and the consequential lifestyle and life experiences represented by it. In many respects, Playboy magazine can be considered a milestone in the history of press publications, having a well-defined target group in America. Playboy is based on a rather sophisticated set of values and lifestyle examples which were acceptable for the majority, and therefore marketable; based on sexuality (one of the most basic of human needs), using the tools of pornography, and thus integrating sexuality into the 'mainstream' media. The main reason for its unbroken success in America is the ability of the magazine and the related media business to continuously renew itself and the long-term relevance of the ingeniously formed basic concept, according to which, every man (and of course, woman) who pays attention to themself is entitled to light entertainment and relaxation, involving physical and mental pleasures. This concept still works perfectly if managed well, and is re-packaged and perhaps slightly repositioned according to the changing fashions of our age. One no longer needs to fish out the magazine from under the desk with downcast eyes, or purchase it with guilt, 'accidentally' mixing it in with the daily paper; these days one can buy it simply and elegantly together with major political and economic magazines as a colourful supplement and enjoyable after-work read. We no longer need to think of whether it is right at all to look at all of the naked women on the pages of a magazine, because they are only coloured points and parts of a more beautiful and happier world; difficult issues, such as pornography, the responsibility of individuals or other people and the environment are no longer relevant: we only passively look at the world going by and lay back a little while for our own relaxation and pleasure. The

2 Hugh Marston Hefner (born April 9, 1926) is an American magazine publisher, founder and Chief Creative Officer of Playboy Enterprises. 
ingenious feature of the concept described above is that it creates a perfect copy for consumer society. It creates a person who likes his job, likes working, is success-oriented, yet has a need for quality leisure time and is willing to invest time, money and energy into his entertainment and hobbies. He is not especially worried about moral issues, yet he respects the law to the required extent because he intends to enjoy everything he has created. He is bothered by his environment only to the extent dictated by current fashion, and he does not ask unpleasant questions about environmental pollution or human rights. He simply creates something and then consumes it. The American magazine has retained its success for decades based on its capacity to adjust to even the most extreme changes in the cultural milieu through its ability to create a marketable and credible philosophy of life. Consequently, the secret to the overwhelming success of Playboy is the existence of certain social conditions. I assume that the existence of this correlation can be scientifically proven with the presentation of the failure of the Hungarian version, because all the conditions that existed in the United States in the second half of the twentieth century were fundamentally different from the attitudes or set of values of post-socialist Hungarian society.

In socialist Hungary, Playboy was available only in a limited number of copies and therefore Hungarian readers looked at it as a magazine with 'distorted' and symbolic content which failed to reflect reality, and one which was sweetened with the 'American dream'. In the end, the magazine was also issued in Hungarian within a few years after the system change, but after its initial success, only very few people read it. According to available sales figures, it seems that Playboy did not reach the segment it was originally intended for. Consequently, we may assume that the original target group did not even exist in Hungary, given the special development track of Hungarian society. The purpose of this study is to prove the validity of this assumption based on the distribution data of the Hungarian version of Playboy magazine, while also taking into account all factors which potentially affected sales.

\section{PORNOGRAPHY BEHIND THE IRON CURTAIN}

According to the official ideology of socialism, there is no such thing as public sexuality. Socialism is a genderless society in which man only exists as a member of the labour movement, as a means of labour. During the socialist era, Hungary was a place where Playboy, labelled pornography, was confiscated at the border, and libraries kept Hungarian and foreign publications which contained pornographic and erotic material (that is, those 
which contradicted the spirit of socialism) in a section reserved for seized publications. Although there is no exact data on the matter, there were surely quite a few people in the 1960s, 1970s and at the beginning of the 1980s who closely guarded various erotic or pornographic books and magazines. Erotica first appeared in public with the emergence of Ciccolina ${ }^{3}$ at the end of the 1980s. Ciccolina, and through her, the 'little sexual revolution' of the time, played a significant role in the relatively rapid establishment of a large tabloid press base. In a bow to the public at large, the 'official' press, albeit grudgingly, catapulted the porn star to celebrity status, using her as a tool for attracting audiences to its programs for the masses, and analysed her in its intellectual niche programmes. The star's media appearances coincided with the inception of the video era. Accordingly, due to the increasing number of home video recorders, more and more people gained access to the now classic films of the artist and her colleagues. Simultaneously, with the appearance of Ciccolina - and not independent of the effect she had - the Hungarian media and content market, in its nascent stages of liberalization, began to operate as a significantly more complex system than before; a system that in many respects also started weighing up business considerations. Although the tabloids and frequently tabloid-style cable channels appeared on the market as early as the beginning of the 1990s, the birth of the real mass media in Hungary and the appearance of national commercial television stations did not come about until 1997. The tabloid press has always been eager to turn to the sex and porn industry for material. However, their relationship became inseperable by the persistent demand for this material on the part of RTL Klub and TV2 television channels and the tabloids (Blikk, Mai Nap, Szines Mai Lap, Story, Best, Star, Party, Villám, etc.), which escalated to the level of mass-media in the last third of the 1990s primarily as a result of the activities of the aforementioned two TV channels.

\section{PORNOGRAPHY IN THE MAINSTREAM MEDIA}

A number of media theorists have proclaimed that the age of mass media is drawing to a close. By this, they generally mean that the possibilities offered by new technologies (digital TV, the Internet and third-generation mobile

\footnotetext{
3 Ilona Staller (complete name Anna Elena Staller, born 26 November, 1951), also known by her stage name la Cicciolina, is a Hungarian-born Italian porn star, politician, and singer. She continued to make hard core pornographic films while in office. She is famous for delivering political speeches with one breast exposed.
} 
networks) are lifting the barriers to distribution, allowing substantially greater access to more content and more types of content than before. Thus, it is precisely this diversity which impedes the emergence of a culture of mass quality. An increasing number of channels are coming into being, providing increasingly personalized content. In Hungary, the emergence of the media market more or less coincided with the global process of the canonization of pornography. Consequently, Hungarian consumers had the opportunity to partake in the blessings and curses of the phenomenon at practically the same time as their Western European and American counterparts. The initial effect of the appearance of porn stars in the media was not to canonize pornography, but to canonize dialogue on the subject of pornography. Meanwhile, of course, their appearance allowed greater room for the depiction of nudity and erotica. Accordingly, the depiction of the pornographic act itself is given the chance to appear in the mass media. The prudish mass media, which has to pay attention to the regulatory authorities and comply with legislation, while being simultaneously required to strive to satisfy a sufficient number of viewers, readers, listeners, and users, is always a step behind the times. It speaks of hardcore but presents it through softcore. At the same time, ever since the penetration of commercial television, news programmes are increasingly adopting the features of entertainment shows both in terms of form and content. These programs are characterised by colourful visual representation, dynamic close-ups and quick cuts. Important news is neglected, and novelties are moved to the spotlight. In addition to or instead of political events, news programs are concerned with the lives of stars, sensation and scandals. Events are dramatized and depicted in a way that is personalitydriven. Processes and correlations behind underlying events remain in the dark. This phenomenon is denoted by the expression 'infotainment' which refers to the words 'information' and 'entertainment'. The appearance of infotainment is explained by commercial channels' efforts not to lose politically apathetic viewers, even during newscasts. Its evolution into the mainstream gives rise to a change within pornography itself. Parallel to its infiltration of the mainstream, pornography plays an increasingly significant role in underground culture as well. Cramer and Home (Cramer and Stewart, 2005) consider avant-garde pornography to be the first significant cultural movement of the new millennium, the main space and distribution channel of which is the Internet. They add, of course, that independent porn is like independent rock music; the point is that it seems to differ from industry standards. However, in reality it works on the basis of similar principles and reinforces precisely similar patterns to mainstream material. According to Cramer and Home, avant-garde (extreme) porn will be the saviour of the 
industry, as 'traditional' porn has merged into mass culture and this process has obliterated its previously established business model. In their view, hardcore porn is for the most part freely available on the Internet and via cable television channels. Consequently, those who intend to make money in this field - as the spiritual father of Playboy magazine Hugh Hefner would presumably like to - will have to offer something special.

\section{HUNGARIAN NEWSPAPER PUBLISHING DATA BETWEEN 2001 AND 2010}

One of the most important indicators of the success of a magazine is the satisfaction of reader requirements; that is, indirectly, the number of sold copies. The data from the graph below (Figure 1) show that the popularity of this magazine began to drop dramatically, reflecting not only the failure of a few issues, but also the rejection by the market. Compared to a linear trend line, a negative trend is evident: if we assume all other factors as being equal, then by the second half of 2004 the average number of distributed copies was around 30,000 , which reflects a nearly $50 \%$ decline over three years.

Figure 1 Distributed number of copies: January 2001 - December 2004

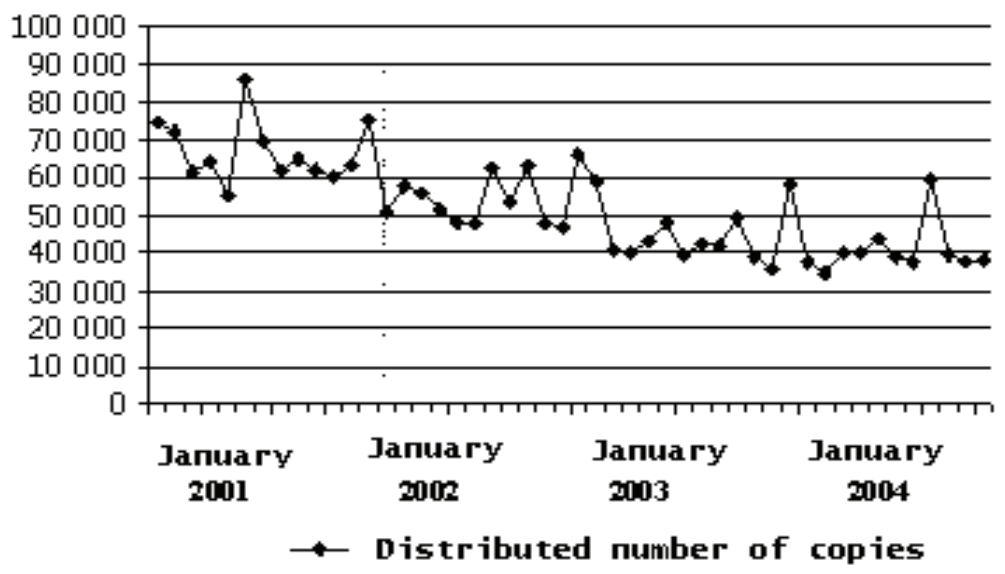

Source: JMG Distribution Department 
Annual period trends can be observed in relation to the January and summer issues. In all three analysed years, there is a relatively simple explanation behind the increase in the number of copies sold in January: customers received a current Playboy calendar with these issues. These promotions are always successful because they boost sales compared to the December figures. The calendar raised sales figures by $16 \%$ in 2002 , and by $37 \%$ in 2003 . In analysing the January distribution figures for each year, we can conclude that while in 2001 the successful January start of the year sales were exceeded and closely followed several times during the year, the same cannot be said about 2002 and 2003, and in fact, examination of the January figures reflects a decline in the number of copies distributed. Accordingly, we can see that the initially successful calendar has by now lost its attraction and turned into a cheap idea, reflected in a decline in distribution of nearly 9,000 copies. It seems that the targeted elite no longer wish to have large calendars displaying pretty ladies, and that a poster recalling the banned eroticism of the 1980s no longer conforms with the consumption patterns or lifestyle of this group. The one or two outstanding sales figures observed in some specific years require further explanation. The Playboy issue deemed the 'most successful' came out in June 2001. Considering the strong influential power of the cover page and given the image created by Playboy magazine, one would presume a strong and extremely erotic lady was shown on the cover. However, the truth is different. Based on customers' decisions, the cover page of the most successful issue ever showed singer Sarolta Zalatnay at the peak of her career, at age 54, which can under no circumstances be deemed young ${ }^{4}$. This outstanding result, which was caused by the front page coverage of a tabloid actor whose private life was full of scandals, has not been repeated since. Although continuous efforts were made, the number of copies distributed and the attraction of the magazine has deteriorated almost continuously. In 2001 and 2002, of twelve models shown on the cover page (ten of whom were Hungarian, and in whom editors expected outstanding interest); the number of copies sold did not increase and the figures of the previous year could not again be attained. Comparing these data with a linear trend, the continuous decrease in the number of sold copies of the magazine is evident. Assuming no other conditions change, based on this trend, Playboy will lose its readers within a few years. In addition to analysis of the data available for 2001 and 2004, the data for the subsequent period are now also available. In the fourth quarter of 2008, the aggregated number of distributed copies was 35,869,

4 Further information: http://en.wikipedia.org/wiki/Sarolta_Zalatnay 
while according to the MATESZ flash report (Hungarian Audit Bureau of Circulations) published on 9 December 2010, the total number of Playboy magazines sold had fallen to 20,046 in the third quarter of 2010. In looking at the figures, we can say that the decreasing trend, reflecting the assumptions of this study, has not turned around even according to the latest figures. This piece of research now determines the target group of the Hungarian edition of Playboy, and looks at each factor which may theoretically affect its sales figures. Our objective is to prove that, apart from the initial excitement which surrounds a new launch and the brand awareness and specific issues which attracted a lot of interest, the conditions for Playboy's long-term success are not in place in Hungarian society.

\section{TARGET GROUP AND READERSHIP OF THE HUNGARIAN EDITION}

In Hungary, Playboy celebrated its seventh anniversary in 2005. Following its initially overwhelming success, the magazine became less and less popular, which is clearly illustrated in the reduction of the number of sold copies and in the declining number of readers. What could be behind this development? Will Playboy disappear from Hungarian society? May a solid reader base never have existed? Have its readers' demands and requirements changed? Do they satisfy their needs for information from other media these days? Or has the entire social segment changed, and does Playboy no longer fit in? Similarly to other magazines, has there been a shift between targeted, potential readers and actual readers which also holds true for Playboy? The success of the magazine is affected by the size of the intersection of the two groups and whether the authors of the magazine manage to reach their target groups in society. In terms of its population, Hungary is one of the smallest countries in which Playboy is published, therefore it is worth considering whether the international positioning of Playboy, which works so well elsewhere, can be applied effectively to the Hungarian market. When Playboy was launched on the Hungarian market, it targeted the following groups of society: men, aged 18-49, people living in towns, and those classified as being in the $\mathrm{AB}$ category according to ESOMAR criteria. According to these specific criteria, the following potential reader figures emerge (January 2004):

Men:

$3,940,000$

Men, aged 18-49:

$2,377,000$

Men aged 18-49 and living in towns:

$1,479,000$

Men aged 18-49, living in towns, with AB status:

291,000 
As an empirical indicator, it can be estimated that $10 \%$ of the number of potential readers of the magazine from the target group will become regular customers of the magazine. In the case of Playboy, 29,000 copies could be sold (by the end of 2010, the total average number of distributed copies was only slightly higher than 21,000). The average of 80,000 distributed copies which was set as the target at the time of the launch can only be reached if the target group is 'complemented'. Naturally, some economically-driven criteria (primarily 'snob impact') are also indicated here and may have increased the number of customers; however, lasting success cannot be based on this. Consequently, there was some uncertainty even in positioning, the impact of which could be felt only a few years after the launch. However, the primary reasons for the increasingly frequent failure of Playboy (the gradually decreasing number of sold copies) are not due to demographic differences. The main reason lies withstatus. Within its own category, Playboy is targeted at the absolute elite and charges the highest price (795 HUF). The authors of the magazine choose to write for the elite; that is, the people who, based on their economic power, are not only capable of but also willing to buy the magazine each month.On the other hand, experience shows that the targets and results do not correspond with each other. In terms of wealth, $16 \%$ of the Hungarian population falls into the elite category (AB status), while among Playboy readers, this same segment is $19 \%$. Contrary to expectations, we cannot talk about any significant difference or 'over-representation'. The majority of Playboy readers ( $25 \%$ ) belong to the $\mathrm{C} 2$ category and to the lowermiddle class. The elite is no longer interested in the magazine and although it is designed for them, the majority of its readers belong to different categories. Approximately $25 \%$ of the readers of the Hungarian edition of Playboy have an outstandingly high income and belong to the A-B social status group, where the purchasing power index is clearly high; close to $50 \%$. Readers who own a car, which is the major component of their lifestyle and a status symbol for them, stand at $67.2 \%$. Their consumption is determined by fashion and brand orientation; they are open to new things, tend to make decisions fast, enjoy any kind of shopping, prefer international brands and belong to the group of people who collect experiences. Readers who enjoy travelling and those who, at the time of research, were planning to go on holiday for more than five days over the next year tallied in at $56.6 \%$ and $68.6 \%$, respectively. A car is their main lifestyle component and one of the central topics of interest for Playboy readers: $67,2 \%$ of the readers have a car and $10 \%$ have more than one car, while a further $39 \%$ plan to buy a car. In terms of musical preferences, $80.1 \%$ are interested in light music and like spending their free time listening to music. They also like learning about the latest developments in the financial 
world: $33.8 \%$ seek out profit-generating investment options for their capital and $20.9 \%$ regularly check out advertisements regarding financial services. For $85 \%$ of Playboy readers, the body and beauty care and a high-quality appearance are important issues; $61.9 \%$ are interested in current fashion trends. Consequently, they always look for special new products and generally prefer good-quality, branded products. Readers interested in sports events and the latest technical developments related to them, and those who try to keep up with developments in technology number $67.3 \%$ and $66.2 \%$, respectively.

\section{PLAYBOY READERSHIP AS A REFLECTION OF THE HUNGARIAN NEWSPAPER MARKET}

This chapter illustrates that although the Hungarian edition of Playboy magazine is read by readers representing an extremely wide social base, they are still not satisfied with their financial status or big-city lifestyle, and are not open-minded and do not possess a wide range of interests, which would clearly separate them from the readers of other lifestyle magazines available in Hungary and would also connect them with the readers of the American magazine. We hereby try to capture any correlation by using a program containing the responses to (a maximum of) 16,000 interviews a year, updated quarterly by TGI Hungary.

TGI consumption status measures status for entire households; that is, it ranks every member of a household into one and the same group based on the characteristics of the main breadwinner in the household (occupation category, highest level of education), as well as the household's income and wealth position. By definition, of those living in a household the person who contributes most to the household's income counts as the main breadwinner in the household (that is; the one who makes the most money). This variant is generated on an index basis. The structure of the TGI consumer status Builder variants include:

- ESOMAR social category (qualifications-education)

- per capita income groups (equivalence income groups)

- wealth status groups

The Esomar social category system was transformed into an eight-step scale, in which 1=Status Group "E3" and 8=Status Group "A". Per capita income groups also comprise an eight-step scale (weighted by the number of household members), on which 1=per capita income below a certain amount of Hungarian forints, and 8=per capita income above a certain amount of Hungarian forints. Wealth status is measured through an index generated on 
the basis of the ownership distribution of forty kinds of assets and durable consumer goods. We also converted this contiguous index variable to an eightstep scale, in which $1=$ 'the household is poorly furnished with possessions' and $8=$ 'the household is very well furnished with possessions'. The baseline variables described bear identical weight when the TGI consumer status is generated.

I ran multiple-stage filtering in the course of using the program, the results of which are shown in the diagrams that include figures in the Annex. Before presenting these results, however, I must point out the fact that only publications whose publishers were willing to spend money on this method of data collection were examined with the software.

With the help of the program, we made selections at several steps, the results of which are illustrated in the figures below. Of the numerous correspondence figures prepared during the analysis, we shall firstly present those which help identify certain participants in the magazine market according to certain criteria with the help of the program and then secondly define the readership of three magazines, Playboy, CKM and FHM. We finally specify the variables which affect readership. With the help of this program, we prepared a snapshot of a segment of the printed press; that is, weekly and monthly women's magazines and men's monthly magazines. We used women's weekly and monthly magazines in the analysis for the purpose of proving the initial hypothesis, according to which the readers of men's monthly magazines were significantly different from readers of other printed media. The hypothesis was proved, as is illustrated in correspondence table No. 1 (Figure 2). The readers of the specified newspapers are represented on the vertical axis, and the various demographic data were added to the matrix horizontally. In analysing the figure, it is clear that the x-axis is the age axis, which trends downward from left to right. Gender is also indicated along the X-axis: the left side of the figure is dominated by women and the right hand side is dominated by men, although this distinction is slightly forced in relation to magazines popular within the younger age group. The y-axis corresponds with qualifications, and rises from the top towards the bottom. The individual segments can be relatively clearly separated along the axis. The first quarter contains newspapers offering light entertainment at a cheap price and of a slightly lower quality. This segment may also be described as the 'light, cheap weekly magazines' segment. These magazines (Little Lady, Surprise, Kiss and Tear, Tina, Lady's World) are clearly read by women with lower qualifications who live in the countryside, and for whom short and light articles offer adequate entertainment. 
Figure 2 KMR Software Correspondence Analysis: Womens, mens weekly and monthly magazines

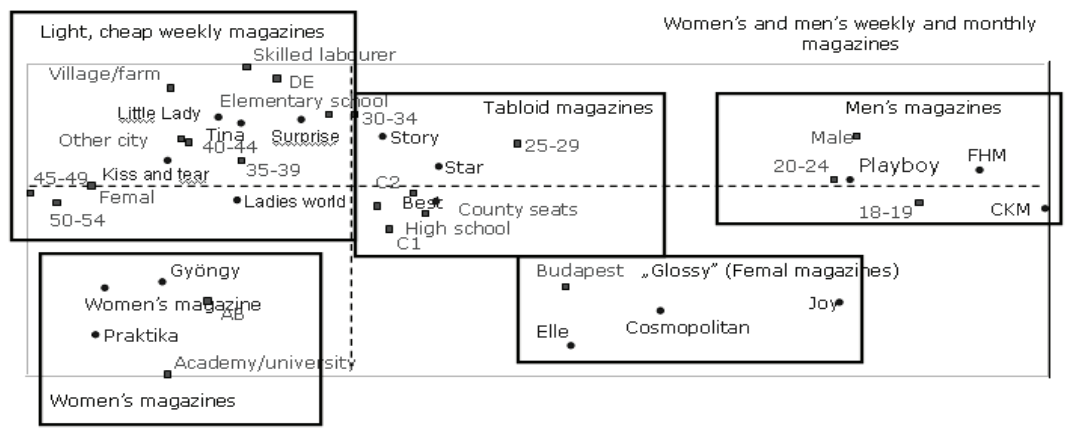

KMR Software Software Cornespondence Analysis

As the figure also shows, tabloid papers have a defined segment in Hungary. It is clear that for middle-aged people with secondary qualifications, generally living in the countryside, the weekly Story, Star and Best magazines are a typical form of entertainment. Nök Lapja, a classic Hungarian product, which has been present on the magazine market for more than fifty years, and women's weekly magazines, its direct competition segment, are slightly further away from the tabloid newspapers. In this segment, Nök Lapja has some specific attributes which can be matched only by competing magazines Gyöngy and Praktika, which have tried to mirror it. Family, external and internal harmony and cultural traditions are the most important features of this segment. As I stated earlier, magazines in Hungary are a completely different segment to weekly papers. From a magazine theme perspective, there are men's and women's magazines. Within the women's magazines category, Joy targets the youngest teenage, Cosmopolitan, the young adult, and Elle, middleaged women. Reading women's magazines is clearly a favorite pastime of Budapest residents. With regard to men's magazines (Figure 3), it is clear that a segement exists which is strongly separate from the other sections of the printed press market. The readers are clearly young men. Given the distance and position of demographic variables, further analyses cannot be performed without modifying the variables, and therefore a new figure had to be created. Based on the segmentation of the previous figure and in continuing the analysis, I highlighted only men's magazines and assigned the various 
demographic criteria to the primarily observed components. As approximately $20 \%$ of the readers of all three magazines are women, I continue to include the gender variable among the set of variables. The total variance of the table is $100 \%$, distributed almost evenly along the two axes. Looking at the malefemale aspect, it is clear that the most 'manly' magazine is Playboy because this aspect is the closest to this magazine in Figure 3, although we must not forget that it is rather close to the axis, which slightly reduces the strength of this explanation. Since I looked at men's magazines in terms of content, it was clear that 'woman' as a criterion defines a separate segment which can also be referred to as the quarter of non-typical characteristics. This is because the least characteristic features of readers of the selected magazines are being a woman and having low socioeconomic status. Having $\mathrm{C} 1$ status and being of the ages 18-19 are slightly further away, but they are not chracteristics related to any of the magazines either. Further criteria which also have weaker explanatory power are situated near the origo and the axis. These criteria are the 'Adventurer' and 'Limited, traditional' categories and the 25-29 year-old age group.

Figure 3 KMR Software Correspondence Analysis: Men's Magazines

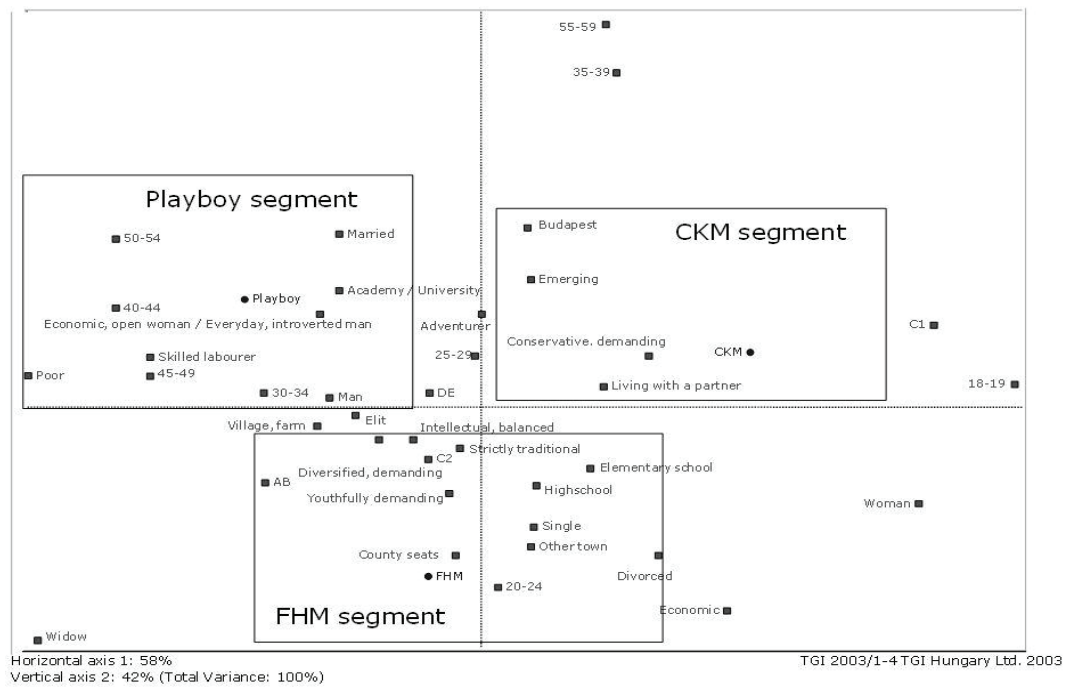


It was easier to define the specificities of Playboy and the characteristics of its readership, than using the Szonda Ipsos data ${ }^{5}$ reflecting demographic information and interests. Consequently, Playboy can be defined as being a magazine for middle-aged men, who are 'Average, compromising men' with specific school qualifications. A vocational school and a university or college diploma are both characteristic. Perhaps this is the point which captures the duality represented by Playboy: naked women and high quality literary works offer interesting reading for two groups with completely different qualifications. In terms of family status, most Hungarian Playboy readers are married, which slightly negates the international attacks against Playboy according to which it challenges traditional institutional systems, including marriage. Most $C K M$ magazine readers 'Have a partner', are 'Conservatively demanding' and are 'Emerging' Budapest residents. No specific age can be defined. Although the older age group of 55-59 year-olds in addition to 35-39 year-old individuals can be found in this quarter, given the huge distance it cannot be considered a major characteristic feature.

According to the correspondence figure, $F H M$ is clearly a magazine for young 'Single' or already 'Divorced' men, living in the country who have 'primary school' or 'secondary school' qualifications and are 'Youthfully daring' in terms of character. According to the analysed criteria, readers of the Hungarian edition of Playboy magazine cannot be singled out as being distinct from the readers of the other lifestyle magazines available in Hungary, and nor can we find any correlation which would connect them to readers of the American edition.

\section{$P L A Y B O Y$ - READER-BASED FOCUS GROUP RESEARCH}

The gradual decrease in the number of sold copies of Playboy suggests reader dissatisfaction, negative developments in the market conditions notwithstanding. The magazine was launched on the market to great fanfare, and the first copies sold out in just days. However, this initial enthusiasm has decreased significantly and we assume that the changes in society during the years after the system change did not lead to the development of a segment which could have become the primary target group of Playboy, based on its concept and standards of life. In fact, questions arise as to how today's readers can be described and who reads the magazine. Has Playboy become only one of a number of magazines unable to achieve its mission in Hungary?

5 (GfK Hungária - Szonda Ipsos National Media analysis, 2008. I-II. quarter) 
To answer this question, I analyzed a group interview detailed below. The relationship between the magazine and Playboy readers can be understood within the framework of focus group research.

Concerning methodology, the focus group research was conducted in the following form. Research was arranged and conducted by the Szonda Ipsos Media, Advertisement, Market and Opinion Research Institute ${ }^{6}$. A total of six focus group interviews were conducted in Budapest, Győr and Debrecen. Group headcounts ranged between six and eight people. One half of the group was comprised of some of the magazine's frequent buyers, while in the other half of the group were men who once used to read the periodical but no longer do. Discussions were facilitated in accordance with the "Monte Carlo" focus group research rules. The study included questions which provided all but complete freedom to respondents, and included asking for ratings regarding various characteristics of the magazine (from poor to excellent) and information regarding the purchase intent scale.

The respondents were very forthcoming in the focus group. After the first few minutes, it turned out that everybody in each group had some old memory or connection with Playboy. The result of the conversations can be summarised in the following statements: It was often mentioned that after the system change, society was open to almost all luxury items coming from the West. Dreams which were suddenly available and achievable were attractive, even if some of them were pricey. Playboy has never been a cheap monthly magazine. Its price is a distinctive feature of the publication which is associated with America's number one men's magazines. It was once a bombshell on the market, but it seems that now the noise from the explosion has settled down. These days there is no tense waiting for the new issues of the magazine to come out; it is not purchased on the same day it is published, and decisions to buy it are rather impulsive. In line with the American image, anybody who buys Playboy does not need any other magazine with similar content, because Playboy contains all the necessary information for the month both in content and in quantity which is required by busy modern people for light entertainment, so only a few other newspapers may be needed as a supplement. Playboy fully succeeds in this mission in the United States. However, the situation tends to be different in Hungary: as it turned out, it is extremely rare that Playboy is bought on its own, as it is generally supplemented with other newspapers and products sold by newsagents and the post office. Although no respondent stated this clearly, we can talk about

6 Ipsos Media, Advertisement, Market, and Opinion Research Institute, founded in 1990, is a dominant player in the Hungarian economic and social research industry. 
it being a 'hidden purchase' in Hungary. Unfortunately, Playboy could not grow out of being associated with pornography, and although the conclusion may seem exaggerated, no group has developed within society as the obvious target group for Playboy, whose members would clearly admit to reading it in front of third parties. Despite the fact that Playboy is usually bought along with other press products, customers are generally aware of its actual price. The price of the magazine is not increased frequently, but according to the pricing policy, it seems that it intends to be significantly more expensive than its competitors. Playboy is generally bought together with CKM and FHM magazines, but the concurrent purchase of the three magazines is not at all typical.

There have been significant changes in motivations for purchase over the last few years. When Playboy appeared in Hungary, it suggested 'luxury' and was one of the symbols of the 'West' in Hungary, which was regaining its breath after the system change. At that time, it was 'the only men's magazine', and the possession and reading of it seemed to be a truly manly and modern thing. According to the respondents, the 'nakedness' contained in the magazine is no longer a unique feature, and it has lost its dominant nature as well; but respondents, in the beginning of the interviews, still indicated to the magazine was bought 'due to the girls and the wellknown Hungarian women'. The expressions used during the interviews also suggest that both Playboy and its readers have become more sophisticated and reserved. Parallel with the elimination of nakedness as the primary aspect, the content elements have become more important. Various columns were also mentioned as being among the reasons for buying the magazine, and the longer interviews and recommendations, which are typical features of the magazine, were also highlighted. One of the objectives of a magazine is to retain its advertisers and to publish as many advertisements as possible, within reason. Reader requirements run contrary to this objective: readers look for more interesting articles and pictures in each specific issue. In general, the two contrary objectives cannot be achieved to the mutual satisfaction of the two groups. However, according to what we heard from the focus groups, the advertisements for 'unachievable things' and 'quality advertisements' were a motivation behind the magazine's purchase. The readers of Playboy and men's magazines generally expect a magazine to suggest 'the unreachable' and 'luxury', yet it must achieve this objective 'without creating an impression that it addresses only millionaires'. In relation to the contents of the magazine, the respondents remembered each column clearly. Reader segmentation prepared according to the focus group research is illustrated in Figure 4. 
Figure 4 Reader segmentation based on Focus Group Research

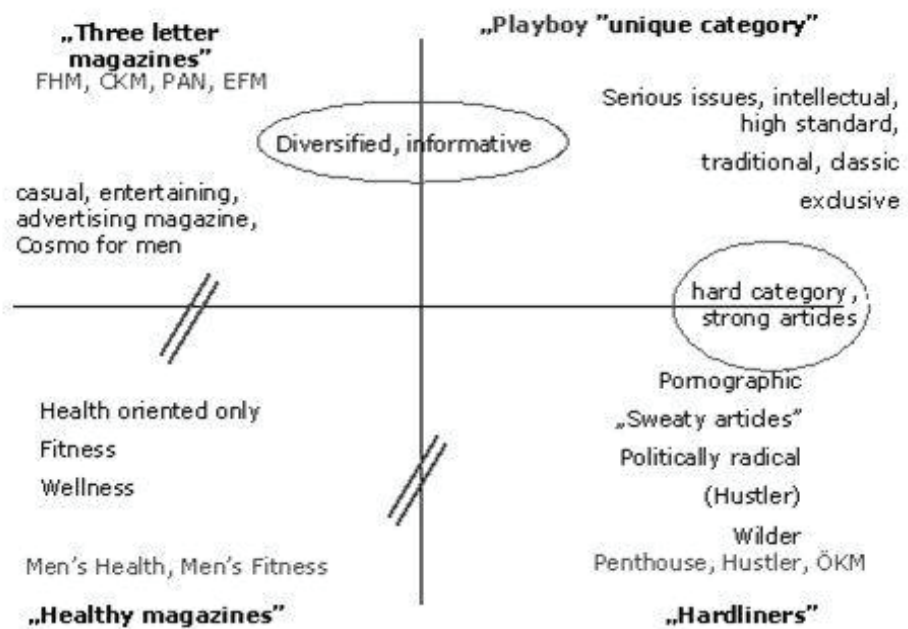

\section{IMPACT OF THE BRAND IMAGE ON SALES}

Last but not least, when we look for an explanation for the initially high number of copies, we cannot forget about the impact of the brand image on sales. Right after its launch, a product does not yet have the values and preferences that consumers come to associate with it, and its success on the market depends on how it can satisfy their requirements. As Geoffrey Randall (Randall, 2000) said: "When soap came in large blocks from which your grocer cut off a slice when you asked for it, you judged it as soap. After Sunlight started to wrap uniform blocks in recognizable packaging, you could begin to differentiate the Sunlight brand from ordinary soap as a product." This differentiation occurred in relation to Playboy because it entered the Hungarian market as a well-known brand, so it was not a product, but much more a brand. According to this principle, if a product, in this case Playboy, offers features to its target group which distinguish it from the other magazines, and based on these features the magazine can offer individual advantages and values that clearly define its 'personal identity', then we talk about it being a brand and not a product. According to the results of the focus group research, we can conclude that Playboy already had attributes when it was launched which allowed it to skip the initial phases of brand building 
as it had an established image. Naturally, it depends on the perception of each individual what is considered unique, but a product is deemed a brand through this mechanism. In her (mainly anthropological) research within the framework of which she looked at brands and their association with cult and rituals, Judie Lannon concluded that "The brand is a cult object...it has charisma" (Lannon and Baskin, 2008). In fact, a similar correlation can also be observed for Playboy, and a lot of related attitudes may be explained through their kind of charismatic nature. The only problem is that as time passes, one's relationship with objects changes and cult products fade away and become everyday items. In the case of Playboy, the brand and related brand image changed, as revealed in the above remarks, and the change generates a major response from the product's buyers. When the brand image is identifiable, consumers develop an overall image in their general thoughts and ideas which may develop from the processing of the information available to them. The information may originate from authentic sources, such as information published by the publisher and the editorial board, or from other sources. From these sources, interpretation of and individual correlation with the brand are affected by societal norms, previous beliefs, selective perception and, last but not least, memory or lack of it. Randall's work points us to the need to introduce another category, brand image, before any further analyses are made. In further considering the previous definition, the theoretical level of the brand must be defined and analysed.The publisher is capable of changing the image developed in relation to the brand by using direct communication; this is the brand image. As the popularity of Playboy and also the interest in the values it represents are gradually decreasing (as indicated by the decreasing number of sold copies), it is worth looking at the brand characteristics of the magazine according to the editorial board, the publisher and the Playboy target group, and identifying the points where differences occur according to the two criteria. Within the framework of the research, I used the brand identity prism developed by J.N. Kapferer (Kapferer, 2008) to identify the differences. To interpret this model we need to identify how the author understands the various brand dimensions. Looking at the model from the 'external appearance' perspective, for Kapferer, the structure is nothing other than the useful value of the product in a stricter sense; more specifically, the following concept: the values mediated by the product which can be identified by analysing the responses to the following questions of 'How does it help?' and 'What is it good for?' In this model, the correlation is based on the fact that the consumer repeatedly purchases products available on the market at certain intervals, an action which triggers a relationship between the newspaper and the reader. For the magazine, the most important 
customers are those people who are willing to spend a certain amount of their disposable income on purchasing Playboy month-after-month. The number of people in this group is gradually decreasing according to the data. Thus by using the model criteria it can be seen that the relationship between Playboy and its customers is getting weaker. The difference, which I touched upon earlier as well (that is, the difference between the target group and actual customers), can be grasped best by describing the reflection of brand dimension. Regarding reflection, Kapferer refers to the type of consumers who are clearly targeted by the brand. This group is not necessarily identical with the target group but also includes those people who, in this case, long for the lifestyle represented by Playboy. The personality dimension is a component of most descriptive models, referring to the fact that it is very important how the consumers of a product, in this case, the readers of the magazine, describe the specific medium. Describing the model from the aspect of internal efforts', it is not even necessary to provide a longer explanation for culture. Each successful product on the market which becomes a major brand carries the culture related to the product, or the producer of the product inside. The name Playboy is identical with America and American mass culture, which is free of any restriction and disseminates the concept of freedom in numerous countries throughout the world. The last, but definitely not the least aspect of the model is self image. For the magazine, this factor is the image that the magazine is trying to create for itself.

\section{CONCLUSION}

Playboy created a world which was happily experienced by young people in their twenties in the hypocritical and morally amplified America of the 1950s, who, full of ambition and enthusiasm, wanted to live a different life than their parents and became tired of and disinterested in wars. For Hungarian readers, meanwhile, it meant everything that was symbolic of the West. The years that followed the system change in Hungary which took place in 1989-90 brought disappointment and disillusion for the majority of Hungarian society, so the long-expected new magazine found a male society which no longer longed for the shiny world of capitalism. Although there was still higher interest in the first few issues, and middle-aged men still bought them, Playboy's readership gradually changed. The older generation, which fetishized Playboy, slowly disappeared and middle-aged, financially strong men simply did not join the group of readers. Business people and male managers, for whom Playboy was designed, were not interested in the sets of values represented by the magazine. 
In Hungary, there was no tradition of magazine reading which was typical (primarily) of Anglo-Saxon countries, and no social demand developed which was able to control or influence the publication of magazines for a long time, while commercial channels offering various international magazines targeted at intellectuals were founded one after the other. This fact is also supported by an analysis of the demographic data of the readership, according to which a large number of readers are inactive, and the ratio of physical workers and skilled workers is also high. Consequently, it is clear that qualifications, occupation and income categories no longer explain the readership figures. Although the Playboy brand name is extremely well-known in Hungary, this awareness stems from imagined components rather than real ones, and from hearing about the magazine rather than reading its issues. As the communities which represent the values of the whole of society are disappearing, reference groups and points of comparison apply only to a much smaller sub-culture, and Playboy, which was able to influence large masses in its early days is also gradually losing its importance.

\section{REFERENCES}

Allen, Judith A. (1987), Mundane Men: Historians, Masculinity and Masculinism, Historical Studies, Vol. 22, pp. 54-68

Beggan, James K., Allison, Scott T. (2001), What Do Playboy Playmates Want?, Men's Studies Press

Barker-Benfield, G.J. (1976), The Horrors of the Half Known Life: Male Attitudes Toward

Women and Sexuality in Ninteenth Century America, London \& New York, Harper \& Row

Beniger, James R. (1986), The Control Revolution. Technological and Economic Origins of

the Information Society, Cambridge, Massachusetts, Harvard University Press

Callen, A. (2003), „Doubles and Desire: Anatomies of masculinity in the later nineteenth century", Art History Vol. 26, no. 5, pp. 14-27.

Chalaby, Jean (1996) „Journalism as an Anglo-American Invention. A Comparison of the

Development of the French and Anglo-American Journalism, 1830s-1930s", Journal of European Communication Vol. 11, No. 3, pp. 303-326.

Cramer, Florian \& Home, Stewart, Pornographic Coding (http://cramer.netzliteratur. net/writings/pornography/london-2005/pornographic-coding.html), (03/11/2011)

Dale, Liza (1991), The Rural Context of Masculanity and the 'Woman Question': An Analysis of the Amalgamated Shearers'Union Suoldalort for Women's Equality, NSW, 1890-1895, Clayton, Monash University. 
Eisenstein, Elisabeth (1993), The Printing Press as an Agent of change, Cambridge, Cambridge University Press

Geoffrey Randall (2000), A practical guide to planning your strategy, Kogan Page

Greek, Cecil E. és William Thompson (1992), „Antipornography Campaigns, Saving the

Family in America and England", International Journal of Politics, Culture, and Society, 5(4), pp. 601-615.

Gulyás, Ágnes (2004), „Western influences in the Print Media of Post-Communist East-Central Europe", The Journal of International Communication Vol. 10, No. 1, pp. 81-106.

Gulyás, Ágnes (2000), ,Tabloid Newspapers in Post-Communist Hungary”, in Sparks, C., Tulloch, J. and Zeliezer, B. (eds) Tabloid Tales: Global Debates over Media Standards, Rowman \& Littlefield, pp. 111-128.

Huer, J. (1987), Art, Beauty, and Pornography: A Journey Through American Culture, Buffalo, Prometheus Books

Hutchinson, David (1996), "Media Policy”, in Jacobs, R. N., Producing the News, Producing the Crisis, Media, Culture \&. Society Vol. 18, No. 1, pp. 373-397.

Imre, Anikó (2009), Identity Games: Globalization and the Transformation of PostCommunist, MIT Press

Lannon, Judie - Baskin, Merry (2008), A Master Class in Brand Planning, Kindle Edition

J.N. Kapferer (2008), The New Strategic Brand Management: Creating and Sustaining Brand Equity, Long Term, Kogan Page

Kimmel, Michael S. (1987), ,The Contemporary Crisis of Masculinity in Historical Perspective", in Brod, Harry. [ed.]. The Making of Masculinities: The New Men's Studies, Boston, Allen \& Unwin, pp.33-50.

Register, Woody (1999), „Everyday Peter Pans: Work, Manhood, and Consumption”, in: Urban America, 1900-1930, Men and Masculinities

Sarikakis, Katharine (Ed.) (2007), Media and Cultural Policy in the European Union, Amsterdam/New York

Tracey, M., Morrison D. (1979), Whitehouse, London, Macmillan

Walden, Kim (1989), Magazines, New York, Marshall Cavendish Corporation

Weeks, Jeffrey (1981), Sex, Politics and Society, London, Longman 